\title{
Resourcing Digital Competence in Product Development: A Computational Study of Recruitment at Volvo Cars
}

\author{
Vasili Mankevich \\ Swedish Center for Digital Innovation \\ University of Gothenburg \\ vasili.mankevich@ait.gu.se
}

\author{
Fredrik Svahn \\ Swedish Center for Digital Innovation \\ University of Gothenburg \\ fredrik.svahn@ait.gu.se
}

\begin{abstract}
Competence renewal is an intrinsic part of digital transformation. However, digital competence is generic competence - it is function-agnostic and not tied to the specifics of a firm's product portfolio. It typically does not fit established institutional structures. Therefore, it is particularly complicated for product-developing firms to develop digital competence, since functional decomposition and profound specialization prevent necessary knowledge mobility.

We adopt a resourcing perspective to analyze how Volvo Cars identified, engaged, and deployed human resources to balance supply and demand for digital competence. Our study relies on over 5000 published job postings, which we compared with the European Skills, Competences, and Occupations (ESCO) framework on the basis of natural language processing. While broadly confirming the idea that digital competence spread from IT departments into mainstream operations, our study also demonstrates asymmetry in the resourcing environment, reflecting tension between emerging and existing structures. Our study also reveals a tendency to close digital competence deficits through external recruitment rather than internal hiring, and by creating new positions rather than replacements.
\end{abstract}

\section{Introduction}

Digital transformation is often understood as a response to disruption, where organizations alter their value creation paths to accommodate a digital technology [e.g. 1]. For incumbent firms, such responses typically center on the development of novel institutional arrangements, allowing for reconfiguration of firm resources in relation to the conditions created through digital disruption [2]. Firms take on such reconfiguration activities with the objective to open up new revenue streams [3], create new organizational structures [4], reform corporate culture [5], or establish new roles and skills [6]. However, firms must also remember that the infusion of new digital technologies alters the nature of uncertainty inherent in innovation [7]. Therefore, digital transformation always include an element of agility [8]. Put differently, it should not be understood as one-off resource reconfiguration, but rather as an open-ended resourcing process, where human and material assets are continuously reinterpreted, reconfigured and reallocated, in relation to the constantly changing environmental conditions.

Establishing such open-ended resourcing is difficult for incumbents in general, and for productdeveloping firms in particular. An important explanation is found in the profound specialization of knowledge for design, engineering, and manufacturing [9], effectively preventing the establishment of new links between remote and historically decoupled parts of a company. While the development and production of physical products typically are managed through independent and functionally decomposed organizations [10], digital technologies generate value if they are adaptable to change, easy to master without specific skills, and accessible for broad, distributed, and largely uncoordinated audiences [11, 12]. Clearly, digitalization put product developing firms in limbo between existing organizational structures, designed for decoupling and information hiding [13], and an emergent, often poorly understood logic for organizing that "reshapes knowledge creation" [14] and rewards "cross-location knowledge flows" [15].

To develop digital transformation strategy that reduces this dissonance and increases knowledge mobility - ease of knowledge dissemination and appropriation [16] - product-developing firms must learn to actively identify, engage, and deploy digital competence [17]. Contemporary research reports on "a growing awareness of the gap between existing and needed digital competences" [18] and describes a general transfer of digital competences from IT departments into mainstream operations [19]. Still, we know surprisingly little about the nature of digital competence deficits, where in organizations such deficits materialize, and how firms act to meet competence demands.

We take on these questions in a study of how Volvo Cars transformed its workforce in response to 
the overall industry trends of connectivity, autonomous drive, and subscription-based business models. In particular, we study how the firm recruited and reallocated human resources to manage digital competence. In our analysis we use natural language processing and an established framework, developed by the European Commission, to assess digital competence in all internal and external job posting ( 5000) published by the company between 2017 and 2020. We use the data to identify digital competence deficits across the organization, to distinguish what types of competence is missing, and to explain how demands are met. The overall question, guiding this research is: How do product-developing firms resource digital competence?

\section{Theoretical Framing}

\subsection{Digital competence}

An organization's core competence is generally understood as a set of key resources and skills that define product development processes, provide access to critical markets, and prevent imitation by competitors [20]. To advance core competence it is attractive for an organization to sustain current focus. This self-reinforcing behavior makes distinctive competence further accentuated, and "organizations become specialized to niches in which their competences yield immediate advantage" [21]. To avoid competence traps [22] firms must concurrently engage in the acquisition of complementary competence that affords exploration of new possibilities, rather than exploitation of old certainties [23].

To some extent, this established, organizationcentric perspective on core competence is falling apart as firms take on digitalization. Reprogrammability and homogenization of data separates digital technology from the functions and services it enables [12]. Since digital technology is function-agnostic, the competence needed to maneuver that technology becomes useful for a broad range of applications, and across previously disconnected organizational units. In contrast to Prahaladian core competence - which is tied to the specifics of a firm's product portfolio, to the coordination of specialized production skills, and to sequential integration of technologies - digital competence is generic competence. While digital competence does not reflect the institutional structures of the corporation, it facilitates entrepreneurial and organizational agility $[17,24,25]$. In digital environments, characterized by uncertainty, variation, and rapid change [7], such continuous competence renewal [26] is vital for long term survival.
Consequently, digital competence should not primarily be understood as an institutional spine of a corporation, but rather as a portfolio of individual competences, i.e. "knowledge, skills, attitudes, and personal characteristics" that can be improved with individual experience and training [27]. Competitive advantage follows from the company's ability to setup and reconfigure this portfolio of digital competence. Such maneuvering involves considerations about how to balance between abstract and concrete competences [28] as well as the general level of digital fluency in the workforce [29]. It also includes the shift from 'component' competence to 'architectural' competence [30], where knowledge and skills about digital technology is widely diffused, from IT departments into organizational capillaries, to permeate mainstream operations [19].

Although it has been debated whether digital competence should at all be recognized as a research topic [31], an increasing number of studies find it urgent to address "the gap between existing and needed digital competences" [18]. Inspired by this 'gap' metaphor, we take on this challenge by studying digitalization as a struggle to meet digital competence deficit. In doing so, we view the activity of setting up and reconfiguring a portfolio of digital competences, carried by individual employees, as a process of resourcing.

\subsection{Resourcing Digital Competence Portfolios}

Resourcing theory differs from the mainstream resource-based view in that it does not primarily focus on the innate features of assets, but rather how these assets are brought into use. In that sense, resourcing implicates a practice perspective [32], where resources enable actors to enact schemas, such as norms and rules of thumb. Resourcing is the creation, in practice, of assets (people, time, money, knowledge, or skill) and qualities of relationships (trust, authority, or complementarity) allowing for such enactment [33].

For several reasons, we find this perspective useful for understanding how established firms develop openended resourcing practices by identifying, engaging, and deploying digital competence [17]. First, the emergent and generative nature of digital innovation [12] prevents making an up-front specification of a competence deficit. The gap between existing and needed digital competences vary as the meaning of assets are recurrently reframed to fit a developing organizational strategy [34]. Then, when the contours of a competence gap starts to materialize it is still difficult to find an appropriate mix of internal and external human resources, and institutional tensions make it problematic to effectively deploy them. In this 
paper we see the maneuvering of such competing concerns [35] as a resourcing process, where various stakeholders engage in complex negotiations as issueselling to advance conflicting agendas [36].

To put digital competence into practical use product-developing firms must find ways to realize new business objectives within the constraints of existing institutional environments [37]. In this paper, we conceptualize the organization as a 'gravity field' of such tensions, where demand and supply pull of competence flow. To dismantle this flow we rely on an analytical framework for assessing resourcing environment, resourcing object, and resourcing action. By resourcing environment we refer to the specific organizational localities where digital competence deficits arise. Resourcing object refers to particularities or characteristics of a deficit. In other words, it focuses on how to distinguish between different types or forms of digital competence. Finally, resourcing actions represent the various initiatives taken to put a particular competence in use and, ultimately, seeking to close a deficit.

\section{Methods}

\subsection{Case selection}

We have studied the resourcing of digital competence at Volvo Car Corporation (from now on Volvo Cars), a Swedish automaker with just over 40000 employees worldwide. While the automotive industry is unique with its own set of challenges [e.g. 38, 39], characteristics such as capital intensity, regulation, cyclic development, transformation pressure are broadly applicable in product development. As such, we look upon Volvo Cars as a typical case selection [40], i.e. a case that is similar to others in the field, and that can help investigate a widely spread phenomenon. Resourcing at Volvo Cars is a typical case in relation to the investigated characteristics: Volvo Cars is an established product development firm (founded in 1927), that has a long legacy of engineering innovation, has highly competent workforce, but is under pressure to transition to digitally powered mobility services ${ }^{1}$.

The contemporary automotive industry is subject to fierce and rapid digital disruption, making it an attractive research setting. It is struggling to accommodate three overlapping traits of digitalization: autonomous driving, connectivity and subscriptionbased business models [41]. Autonomous driving is

\footnotetext{
${ }^{1}$ Illustrated by Volvo Cars "Electrification" and "Future mobility" initiatives.
}

largely about the application of artificial intelligence (AI) for sensing environments and moving the vehicle with little to no human intervention. In combination with connectivity, which integrates the car with other digital infrastructures, automakers now experiment with subscription-based business propositions. Such business models range from simple leasing contracts to ride-sharing and, ultimately, fully automated robotaxis ${ }^{2}$.

These profound challenges bring radically different product architecture, novel organizational structures, and opens up for a completely new market logic. In response, automakers must renew existing competence portfolios [26]. This paper reports on how Volvo Cars implemented such resourcing by identifying, engaging, and deploying digital competence [17].

\subsection{Data}

To study the resourcing environment, object, and action, we had to follow the flow of digital competence at Volvo Cars. All recruitment records at the company were stored in a dedicated HR system. We collected data from that system through direct access provided by a Volvo Cars employee to follow all employee appointments from autumn 2017 to spring 2020 (table 1 and figure 1). All in all, we extracted 5682 job posts, but 1901 were excluded due to inferior quality of job description (too short or written in a language other than English).

The job posts contained information about recruiting department and associated business unit. Since we viewed job post as proxies for competence deficits, such organizational locality reflects the resourcing environment. Further, the posts contained title and a detailed job description, providing nuance information about the type of competence being in demand. Analyzing this data, we could study the breadth of resourcing objects at Volvo Cars. Finally, the recruitment records included information on recruitment type (new position or replacement), recruitment status (filled, in progress, cancelled), and if recruitment was successful the recruitment origin (internal hiring or external recruitment), and recruitment type (new position or replacement). This information allowed us to analyze Volvo Cars' resourcing practice, as they closed competence deficits.

To verify our interpretations, we conducted a series of interviews $(\mathrm{N}=8$, on average 2 hours each) with company representatives throughout the entire data collection and analysis period. The interviewees were members of HR and Innovation divisions and had

\footnotetext{
${ }^{2}$ Special report: Reinventing Wheels. The Economist, March 2018
} 
an intimate understanding of the data stored in the system and the recruitment process. These interviews served as a way to triangulate findings, interpret the context, and examine analysis assumptions and results. The interviewees were questioned regarding the data quality, assumptions embedded in particular aspects of data, they were presented with intermediate stages of the analysis to mitigate potential misrepresentation of the data or recruitment practices.

Table 1. Data collected

\begin{tabular}{|l|l|}
\hline Description & \\
\hline Total recruitment records collected & 5682 \\
\hline Data collection period & Spring 2020 \\
\hline Recruitment period & $\begin{array}{l}\text { "2017-08-14" - } \\
\text { "2020-06-01" }\end{array}$ \\
\hline Records used in analysis & 3781 \\
\hline $\begin{array}{l}\text { Disregarded Recruitments: } \\
\text { empty job descriptions (postings } \\
\text { cancelled by the management, in } \\
\text { which case the description was never } \\
\text { finalized) }\end{array}$ & \multicolumn{1}{|c|}{$\bullet \quad$ 1385 } \\
Non-English & 533 words \\
\hline Average job description length & 3595 \\
\hline Country of recruitment: & 62 \\
$\bullet \quad$ Sweden & 124 \\
$\bullet \quad$ Belgium & \\
$\bullet \quad$ Others & 2164 \\
$\bullet \quad$ New position & 1617 \\
\hline Recruitment type: & \\
\hline
\end{tabular}

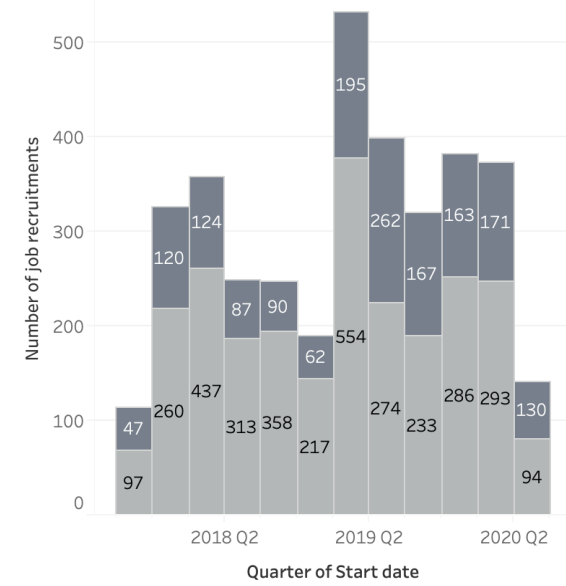

Job posting status

Not filled (recruitment cancelled, in progress, on hold) Filled

Figure 1 Recruitment records

\subsection{Analysis}

Our data analysis rested on three overall steps. First, we identified an existing reference framework for classification of digital competence. We then selected a computational method for applying this framework to the extracted job posts. This move aimed to identify the level of digital competence in postings. We finally adapted this method to compare job post with each other.

Establishing a reference framework. To assess the level of digital competences reflected by job postings, we decided to use the established ESCO framework $^{3}$. ESCO was developed by the European Commission in 2010 and intended as a dictionary "describing, identifying and classifying professional occupations, skills, and qualifications relevant for the EU labor market and education and training”. ESCO includes DigComp, a reference vocabulary for digital competences, developed for a wide range of stakeholders (e.g. educators, policymakers, and companies) to address the rising demand for articulated digital competences [42]. It consists of 5 competence areas, each containing a detailed description and narrower competences (table 2). Each of these narrow competences, in turn, come a textual description and alternative labels, to ensure comprehensive coverage. All in all, DigComp includes 135 unique competences. DigComp represents the middle ground approach for describing competences: defining competences between high-level abstractions and operational-level (tool specific) skills [28]. It is being developed and updated continuously, the most recent version released in 2020. The fact that the ESCO framework has been actively used in previous research [e.g. 43, 44, 45], including information systems, made us convinced of its merits.

\section{Table 2. DigComp ESCO digital competence} areas

\begin{tabular}{|l|l|}
\hline Broad competence areas & $\begin{array}{l}\text { Example of } \\
\text { narrower } \\
\text { competences }\end{array}$ \\
\hline $\begin{array}{l}\text { Problem-solving with digital tools - } \\
\text { Identify digital needs and resources, } \\
\text { make informed decisions on most } \\
\text { appropriate digital tools according to the } \\
\text { purpose or need, solve conceptual } \\
\text { problems through digital means, } \\
\text { creatively use technologies, solve } \\
\text { technical problems, update own and } \\
\text { other's competence. }\end{array}$ & $\begin{array}{l}\text { and navigation } \\
\text { problems by } \\
\text { using GPS tools, } \\
\text { solve technical } \\
\text { problems }\end{array}$ \\
\hline $\begin{array}{l}\text { Digital content creation - Create and } \\
\text { edit new content (from word processing } \\
\text { to images and video); integrate and re- } \\
\text { elaborate previous knowledge and } \\
\text { content; produce creative expressions, }\end{array}$ & $\begin{array}{l}\text { Computer } \\
\text { programming, } \\
\text { use spreadsheet } \\
\text { software }\end{array}$ \\
\hline
\end{tabular}

\footnotetext{
${ }^{3}$ European Skills, Competences, Qualifications and Occupations framework: https://ec.europa.eu/esco/
} 


\begin{tabular}{|l|l|}
\hline $\begin{array}{l}\text { media outputs and programming; deal } \\
\text { with and apply intellectual property } \\
\text { rights and licences. }\end{array}$ & \\
\hline $\begin{array}{l}\text { ICT safety - Personal protection, data } \\
\text { protection, digital identity protection, } \\
\text { security measures, safe and sustainable } \\
\text { use. }\end{array}$ & $\begin{array}{l}\text { Protect personal } \\
\text { data and privacy, } \\
\text { protect ICT } \\
\text { devices }\end{array}$ \\
\hline $\begin{array}{l}\text { Digital communication and } \\
\text { collaboration - Communicate in digital } \\
\text { environments, share resources through } \\
\text { online tools, link with others and } \\
\text { collaborate through digital tools, } \\
\text { interact with and participate in } \\
\text { communities and networks, cross- } \\
\text { cultural awareness. }\end{array}$ & $\begin{array}{l}\text { Manage online } \\
\text { manage digital } \\
\text { identity }\end{array}$ \\
\hline $\begin{array}{l}\text { Digital data processing - Identify, } \\
\text { locate, retrieve, store, organise and } \\
\text { analyse digital information, judging its } \\
\text { relevance and purpose. }\end{array}$ & $\begin{array}{l}\text { Store digital data } \\
\text { and systems, } \\
\text { record test data }\end{array}$ \\
\hline
\end{tabular}

Categorizing job posts. We now had to assess each job posting in light of the ESCO framework. In practice, we had to figure out a way to measure how the 135 digital competences were represented in our data material. Inspired by recent calls for computational methods in information systems [46] as well as management [47], we used natural language processing (NLP) for computational analysis of text. By using NLP we could look into text similarity between job posts and the ESCO reference framework. Given the length of the texts, we used a token-based similarity approach [48], i.e. we measured concurrent use of terms and words. In practice, the texts of job posts as well as the framework were converted into 'bags of words'. Following proven NLP practice, we removed punctuations, symbols, and so called 'stop words' (most common words in English language). The words were also stemmed (endings removed to get to stems of the words). Further, we applied the widely used TF-IDF ${ }^{4}$ method [49] to account for difference in document length and word frequency. With this approach each term frequency is measured for each document (TF). These scores are normalized in respect to the posting length. Then, the inverse document frequency (IDF) for each term is calculated to give a boost to rare terms since they can potentially be important distinguishing features. Lastly, the two measures are combined into a TF-IDF, giving each posting a set of features that represent TF-IDF scores of the terms.

Finally, we used cosine similarity to quantify similarity between each job description and the 135 digital competences of DigComp. Cosine similarity between two documents is measured as an angle between their vectors that measure term frequency in

${ }^{4}$ Term frequency-inverse document frequency the number of dimensions that correspond the number of terms used for comparison. We calculated pair-wise cosine similarity between each job posting and description of digital competence. In our case, it is a measure of how well a particular digital competence is represented in a job posting. It is recognized as a robust approach for text classification and clustering [50], and widely used in NLP. It is particularly useful for comparing texts of varying lengths.

Analyzing difference. While we looked for similarity when categorizing job posts, we then had to turn attention to difference. Therefore, we reapplied the NLP method to distinguish between job postings. To visualize the distinction (see figure 2) we relied on multidimensional scaling, recommended for management research [51]. It is an approach for finding the best approximation for coordinates of $\mathrm{k}$ dimensional representation of a list of pair-wise distances by minimizing loss function. We used the multidimensional scaling approach across two dimensions $(\mathrm{k}=2)$ to illustrate proximity between resourcing objects [52]. Finally, we wanted to see how digital competence differed between business units, and between various types of recruitment. Since the similarity measures provided by NLP were not normally distributed, we could not rely on standardized inference methods, such as t-tests. Therefore, to detect significant difference we decided to use two-sample Mann-Whitney U tests [53].

\section{Results}

Next we use our theoretical framing to analyze the environment, objects, and actions of digital competence resourcing at Volvo Cars.

\subsection{Resourcing Environment: Where does the digital competence deficit appear?}

Following praxis in the automotive industry, Volvo Cars is a functionally decomposed organization. Largely, that means people take on different product responsibilities in different parts of the organization. The specialization following on such decomposition is apparent in our data set, and illustrated in figure 2. The figure relies on multidimensional scaling to compare all job posts with each other, without paying particular attention to digital competence. The distinct clustering conveys the overall message that Volvo Cars' business units were in demand of different competences.

However, when analyzing how the five business units identified demand for digital competence, a different pattern emerged. Our NLP-based method revealed that all business units had searched for and recruited distinct digital competence. Unsurprising 
examples include an IT unit posting for "Senior Software Engineer" (April 2018) requiring "Strong understanding of multiple languages such as JavaScript, Node.js, Java, Python, Ruby". While postings from other departments typically had a functional focus, they often included a strong digital emphasis. For example, the R\&D unit searched for a "Tyre Monitoring System Engineer" (July 2019) requiring both "experience from automotive product development" and "functional and architecture development with focus on the future technology and the integration with the software". Another example was the recruitment of a "Marketing Analytics and AI Manager" to Sales and Market (December 2018), expected to be competent in "AI and Data Science, analyzing information, conducting research".

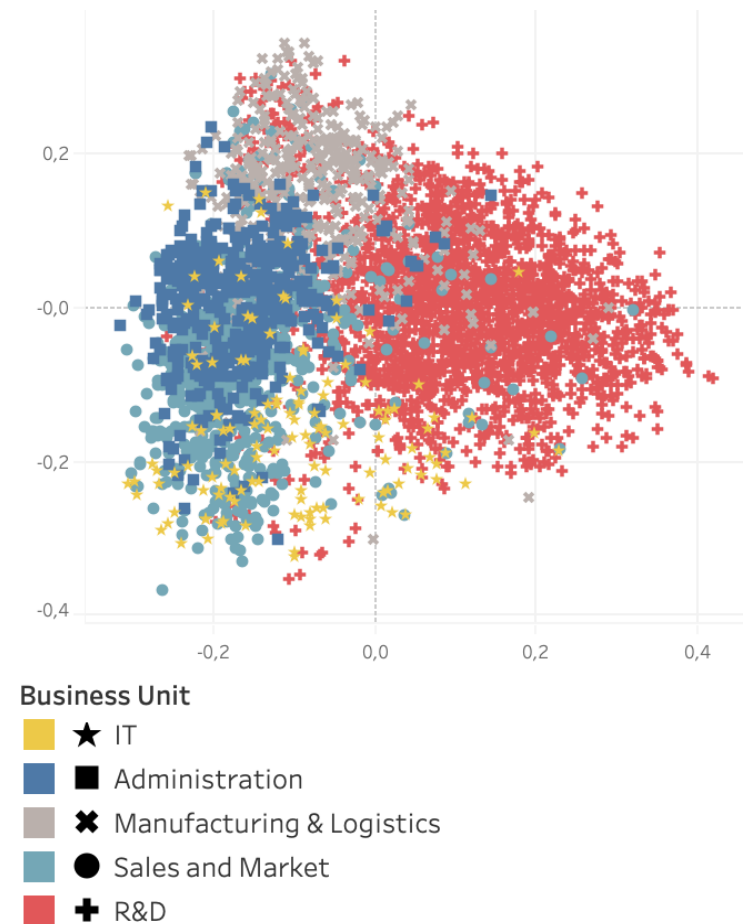

Figure 2. Multidimensional scaling representation of distances in-between job descriptions (by business unit). All text is used (not only digital competences)

Although digital competence turned out to be a scarce commodity across the entire company, a comparison between the five business units revealed asymmetries. Figure 3 presents a distribution of digital competence across all posts at respective unit. Digital competence is measured as cosine similarity between a job post and the ESCO definition of digital competence (see method). The distinctly hump-shaped curves of Administration and Manufacturing \& Logistics reveal that most job posts scored low on digital competence. Although the distributions of R\&D and Sales \& Market have similar form, the curves are substantially flatter. In other words, there are more 'digital' job posts and, consequently, a more salient digital competence deficit. Unsurprisingly, IT sticks out as the unit with highest demand for digital competence.

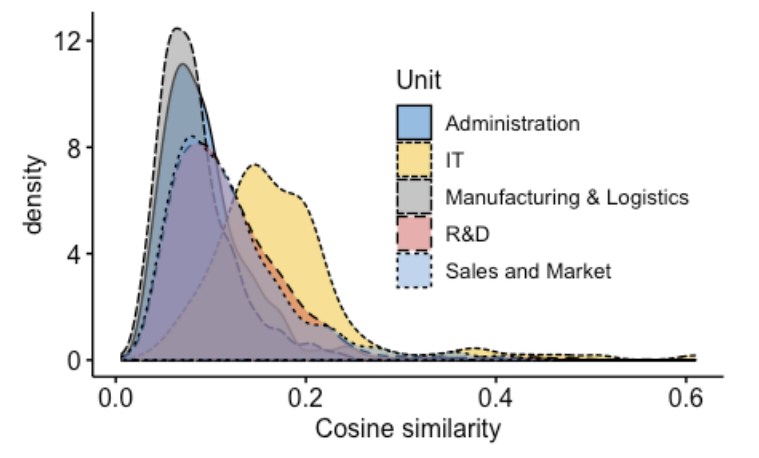

Figure 3

In conclusion, the resourcing environment is a coordinated patchwork of distinctly different competence areas, but where demand for digital competence stretches out across functional domains.

\subsection{Resourcing Object: What digital competences are in demand?}

By resourcing object we refer to particularities or characteristics of a competence deficit. As we shifted perspective, from using the ESCO framework to identify overall, generalized digital competence into studying specialized digital competences, the complexity of the topic grew. We assessed Volvo Cars' job posts in relation to the 135 so called 'narrower' competences and found a great variation in the needs for digital competence.

As illustrated in table 3 that summarizes the three most salient digital competences, unit responsibility is explicitly reflected in the competence deficit of job posts. For example, the R\&D unit searched for "test engineers" and a "data quality manager" interpreted as competence for "analyzing test data". Manufacturing \& Logistics and Administration identified deficit for "developing information security strategy", reflected by job postings for "Information Management Specialist" and "Developer in Cybersecurity \& Privacy". For an illustration of how the 135 ESCO digital competences were in demand at Volvo Cars, see figure 4.

To summarize, resourcing objects differed substantially at Volvo Cars, and the differences are explained by the functional decomposition, ultimately defining tasks at hand. 
Table 3. Top 3 digital competences in deficit

\begin{tabular}{|l|l|l|l|}
\hline Competence & ESCO Description & Unit & Most similar job postings \\
\hline analyze test data & $\begin{array}{l}\text { Interpret and analyze data collected during } \\
\text { testing in order to formulate conclusions, } \\
\text { new insights or solutions. }\end{array}$ & R\&D & $\begin{array}{l}\text { "Data Quality Manager" } \\
\text { "Consumer Data Analyst" } \\
\text { "Manager - Business Intelligence \& Data } \\
\text { Strategy" } \\
\text { "Test Engineer" }\end{array}$ \\
\hline plan digital marketing & $\begin{array}{l}\text { Develop digital marketing strategies for } \\
\text { both leisure and business purposes, create } \\
\text { websites and deal with mobile technology } \\
\text { and social networking. }\end{array}$ & $\begin{array}{l}\text { Sales \& Market, } \\
\text { Administration }\end{array}$ & $\begin{array}{l}\text { "Digital Implementation Lead" } \\
\text { "Digital Implementation Manager " } \\
\text { "Digital and Social Marketing Graduate" }\end{array}$ \\
\hline $\begin{array}{l}\text { develop information se } \\
\text { curity strategy }\end{array}$ & $\begin{array}{l}\text { Create company strategy related to the } \\
\text { safety and security of information in order } \\
\text { to maximize information integrity, } \\
\text { availability and data privacy. }\end{array}$ & $\begin{array}{l}\text { Manuf. \& } \\
\text { Logistics, } \\
\text { Administration }\end{array}$ & $\begin{array}{l}\text { "Information Management Specialist" } \\
\text { "Developer in Cybersecurity \& Privacy } \\
\text { within In-Car Digital" }\end{array}$ \\
\hline
\end{tabular}

\subsection{Resourcing Action: How to resource digital competences?}

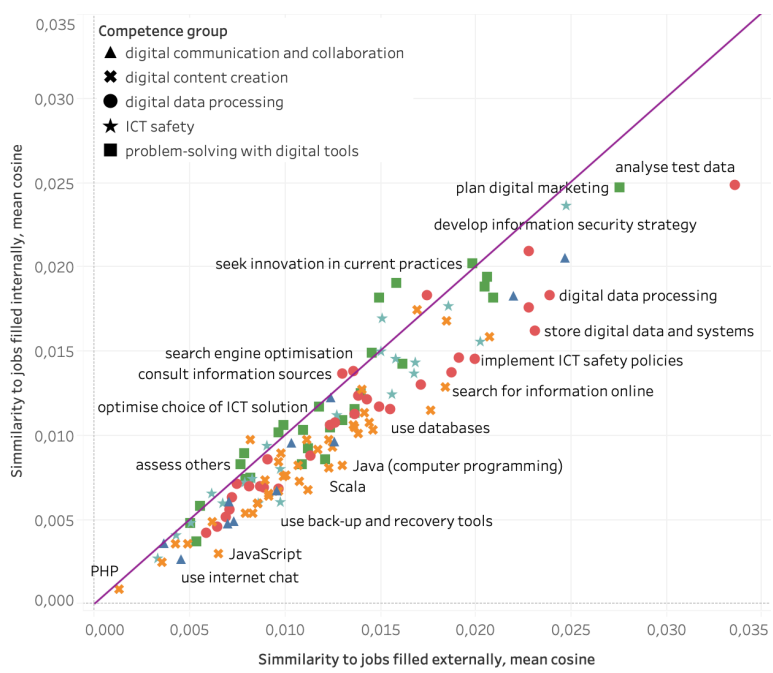

Figure 4. The balance of recruitment between internal and external sources

Resourcing actions are the various initiatives taken to put a particular competence in use, with the objective to close a deficit. First, we approached this issue by sorting out filled positions and distinguishing between internal hiring $(\mathrm{N}=1373)$ and external recruitments ${ }^{5}$ $(\mathrm{N}=1043)$. Our analysis showed that some digital competences were overrepresented in externally filled positions, while other digital competences were more frequently found within the company. Approximately

\footnotetext{
${ }^{5}$ Other forms of recruitment such as conversion of a consultant represented less than a $3 \%$ of all and according to the company HR were a rare technicality. The hire source was explicitly stated for each posting in the HR system.
}

one third of the digital competences showed no significant difference in similarity between internally and externally recruited workforce. Figure 4 provides an overview of digital competences and how salient they were in internally and externally filled postings, respectively.

The bias towards external origin of resourcing objects remains when all digital competences are taken into account. Figure 5 compares the distribution of digital competence for externally and internally recruited jobs. The difference is statistically significant (cosine similarity, Mann-Whitney $\mathrm{U}$ test p-value < $0.001)$.

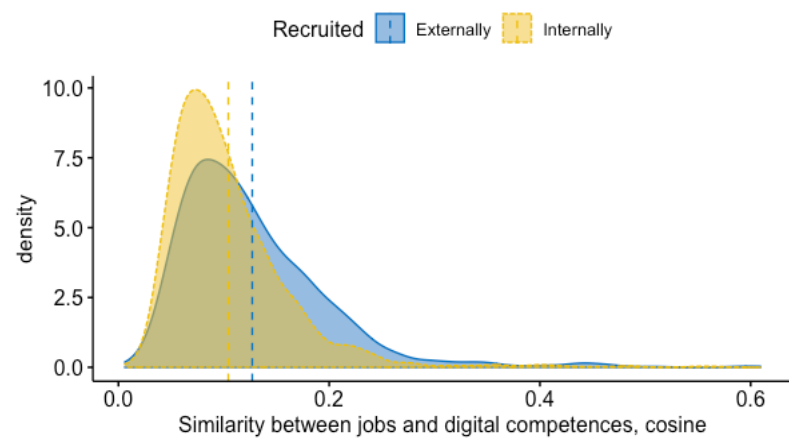

Figure 5. Were digital competences found
internally or externally? Density plot

Next, we tried to understand Volvo Cars resourcing actions by distinguishing between the digital competence of new positions ( $\mathrm{N}=2164)$ and replacements $(\mathrm{N}=1617)$, caused by retirement, transfer, change of job, etc. As illustrated by the distribution in figure 6 , we found that newly created jobs demanded significantly more digital competence than replacements (cosine similarity, Mann-Whitney $U$ test p-value $<0.001)$

To summarize, our analysis revealed (1) a general demand for digital competence across Volvo Cars. At the same time, zooming into the details revealed 
asymmetries in the resourcing environment. While Administration and Manufacturing \& Logistic occasionally signals demand, IT, R\&D, and Sales \& Market frequently searches for digital competence. We also found that (2) resourcing objects differ substantially. While competence deficit in data analysis dominated at R\&D, Sales and Marketing searched for competence in digital marketing. Finally, our study of Volvo Cars suggests that (3) internal vs external and new position vs replacement are useful distinctions when analyzing resourcing action. On an aggregate level, digital competence deficits were more frequently closed by recruiting externally than internally, and by creating new positions rather than replacements.

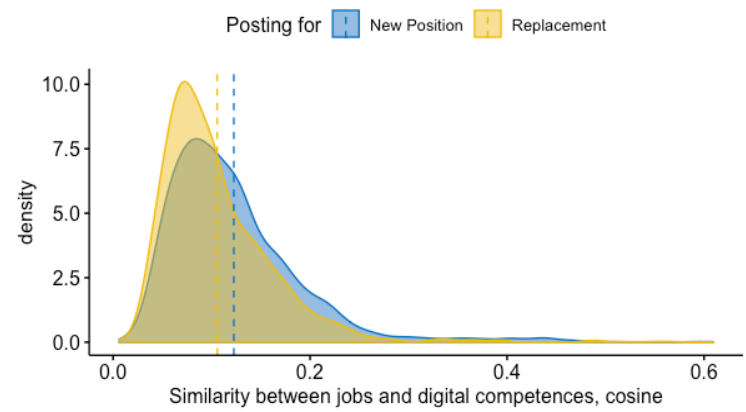

Figure 6. Were digital competences needed more for new or existing positions? Density plot

\section{Discussion}

Digital transformation as a response to disruption [e.g. 1] alters the state of uncertainty [7] and requires agility [8] in open-ended resourcing. It presents a challenge for incumbent product-developing firms, which in the past were thriving through functional decomposition [13] and specialization [9]. Resourcing instead requires decoupling of the structures and unrestricted knowledge flows across organization [15]. To develop digital transformation strategy that reduces this dissonance and increases knowledge mobility [16] product-developing firms must learn to actively identify, engage, and deploy digital competence [17]. In our study of Volvo Cars, we addressed this issue by delving into the environment, the objects, and the actions of digital competence resourcing.

In terms of the resourcing environment, we observed that digital competence deficit is acute in dedicated digital functions (e.g. IT units), but also manifests throughout the organization, including core product areas [19]. The need for digital competence in R\&D functions is expected as digital competences fundamentally change and advance knowledge creation [14]. Resourcing digital competences in other units, such as Sales, may be driven by the increasing interactivity with customers [54] and partners [39, 55] in product development firms. In automotive sector this trend is exemplified by the overall industry demands for connectivity, autonomous driving, and subscription-based business models. Finally, resourcing for digital competences in Administration function may be driven by the shift in organizations from component competences to architectural competences [30], where technological architecture is seen as a critical governance issue [56]. In order to exercise control over digital architectures, Administrative function requires digital competences, which may explain our findings at Volvo Cars.

While the resourcing for digital competence spans the entire organization, an important issue is to recognize great variation in the resourcing object demand for specific and distinct competences. Digital competences can be seen as generic (in contrast to functionally delineated conventional competences), but they are by no means homogeneous [28]. Digital competences are resourced, demonstrating the specific (existing or projected) needs to address firm's interactions with digital technology: the competences for security, programming, communication and problem-solving abilities with digital tools are indemand. Due to recombination [57] and homogenization of the digital [12], the competitive advantage of the companies will stand on their ability to assemble and reconfigure these competences [17].

The resourcing action of finding and putting competences in use is challenging as it requires maneuvering of competing concerns [35] where various stakeholders engage in complex negotiations to advance conflicting agendas [36]. Our study demonstrates how the need for digital competence prompts creation of new jobs positions, while during replacement recruitments the status quo of needed competences is maintained. Furthermore, we suggest that when the existing resources cannot be reframed to fit a developing organizational strategy [34], resourcing taps into external search instead (as seen through preference for closing digital competence deficit with external recruitments).

\section{Conclusions and Limitations}

We acknowledge a number of limitations of this study. The first limitation is related to the theoretical framework that was used. Since we relied on ESCO for building the vocabulary and assessing how digital were the job postings, the outcome is highly dependent on the framework's accuracy in representing digital competences. The second limitation relates to the data that was used. Job postings reflect the "wish list" of the recruiters, not always what competences candidates 
possess. In this regard, our study showed the intention by Volvo Cars to acquire certain competences, but not necessarily the extent to which it was successful. Lastly, we employed a number of computational techniques in combination with qualitative work, which involves the challenges in combining human and machine pattern recognition [58].

In conclusion, our study demonstrates asymmetry in the resourcing environment, reflecting the tension between emerging and existing structures. Our study also reveals a tendency to close the digital competence deficit through external recruitment rather than internal hiring, and by creating new positions rather than replacements. Adopting resourcing perspective, we investigate the environment, object and action of resourcing digital competences in product development. Further studies should investigate how various modes of resourcing and their configurations are needed to address the complex landscape of digital competences and how they interact with digital transformation of incumbent firms.

\section{References}

[1] G. Vial, "Understanding digital transformation: A review and a research agenda," The Journal of Strategic Information Systems, vol. 28, no. 2, pp. 118-144, 2019

[2] B. Hinings, T. Gegenhuber, and R. Greenwood, "Digital innovation and transformation: An institutional perspective," Information and Organization, vol. 28, no. 1, pp. 52-61, 2018 [3] M. Barrett, E. Davidson, J. Prabhu, and S. Vargo, "Service Innovation in the Digital Age: Key Contributions and Future Directions," MIS Quarterly, vol. 39, no. 1, pp. 135-154, 2015

[4] D. Dougherty and D. D. Dunne, "Digital Science and Knowledge Boundaries in Complex Innovation," Organization Science, vol. 23, no. 5, pp. 1467-1484, 2012

[5] J. Karimi and Z. Walter, "The Role of Dynamic Capabilities in Responding to Digital Disruption: A FactorBased Study of the Newspaper Industry," Journal of Management Information Systems, vol. 32, no. 1, pp. 39-81, 2015

[6] I. Haffke, B. J. Kalgovas, and A. Benlian, "The Role of the $\mathrm{CIO}$ and the $\mathrm{CDO}$ in an Organization's Digital Transformation," presented at the International Conference on Information Systems, Dublin, Ireland, 2016.

[7] S. Nambisan, M. Wright, and M. Feldman, "The digital transformation of innovation and entrepreneurship: Progress, challenges and key themes," Research Policy, vol. 48, no. 8, 2019

[8] K. S. R. Warner and M. Wäger, "Building dynamic capabilities for digital transformation: An ongoing process of strategic renewal," Long Range Planning, vol. 52, no. 3, pp. 326-349, 2019

[9] S. Brusoni, A. Prencipe, and K. Pavitt, "Knowledge specialization, organizational coupling, and the boundaries of the firm: Why do firms know more than they make?," Administrative Science Quarterly, vol. 46, no. 4, pp. 597621,2001
[10] M. A. Schilling and H. K. Steensma, "The Use of Modular Organizational Forms: An Industry-Level Analysis," Academy of Management Journal, vol. 44, no. 6, pp. 1149-1168, 2001

[11] M. Avital and D. Te'eni, "From generative fit to generative capacity: exploring an emerging dimension of information systems design and task performance," Information Systems Journal, vol. 19, no. 4, pp. 345-367, 2009

[12] Y. Yoo, "The Tables Have Turned: How can the Information Systems field contribute to technology and innovation management research?," Journal of the Association for Information Systems, vol. 14, no. 5, 2013

[13] D. L. Parnas, "On the criteria to be used in decomposing systems into modules," Communications of the ACM, vol. 15, no. 12, pp. 1053-1058, 1972

[14] K. Lyytinen, Y. Yoo, and R. J. Boland Jr, "Digital product innovation within four classes of innovation networks," Inform Syst J, Article vol. 26, no. 1, pp. 47-75, 2016

[15] C. Forman and N. van Zeebroeck, "Digital technology adoption and knowledge flows within firms: Can the Internet overcome geographic and technological distance?," Research Policy, vol. 48, no. 8, p. 103697, 2019

[16] C. Dhanaraj and A. Parkhe, "Orchestrating Innovation Networks," Academy of Management Review, Article vol. 31, no. 3, pp. 659-669, 2006

[17] P. A. Pavlou and O. A. El Sawy, "From IT Leveraging Competence to Competitive Advantage in Turbulent Environments: The Case of New Product Development," Information Systems Research, vol. 17, no. 3, pp. 198-227, 2006

[18] M. Oberländer, A. Beinicke, and T. Bipp, "Digital competencies: A review of the literature and applications in the workplace," Computers \& Education, vol. 146, p. 103752, 2020

[19] A. Yeow, C. Soh, and R. Hansen, "Aligning with new digital strategy: A dynamic capabilities approach," The Journal of Strategic Information Systems, vol. 27, no. 1, pp. 43-58, 2018

[20] C. Prahalad, "The Core Competence of the Corporation," Harvard Business Review, vol. 3, no. MayJune, pp. 79-91, 1990

[21] D. Levinthal and J. March, "The myopia of learning," Strategic Management Journal, vol. 14, pp. 95-112, 1993

[22] E. Danneels, "The process of technological competence leveraging," Strategic Manage J, vol. 28, no. 5, pp. 511-533, 2007

[23] J. March, "Exploration and exploitation in organizational learning," Organization Science, vol. 2, no. 1, pp. 71-87, 1991

[24] A. Chakravarty, R. Grewal, and V. Sambamurthy, "Information Technology Competencies, Organizational Agility, and Firm Performance: Enabling and Facilitating Roles," Information Systems Research, vol. 24, no. 4, pp. 976-997, 2013

[25] V. Sambamurthy, A. Bharadwaj, and V. Grover, "Shaping agility through digital options: Reconceptualizing the role of information technology in contemporary firms," MIS Quarterly, vol. 27, no. 2, pp. 237-263, 2003 
[26] E. Danneels, "The dynamics of product innovation and firm competences," Strategic management journal, vol. 23, no. 12, pp. 1095-1121, 2002

[27] D. Vieru, "Towards a multi-dimensional model of digital competence in small-and medium-sized enterprises," in Encyclopedia of Information Science and Technology, Third Edition: IGI Global, 2015, pp. 6715-6725.

[28] K. Ala-Mutka, "Mapping digital competence: Towards a conceptual understanding," European Commission, Joint Research Centre, JRC67075, 2011.

[29] A. Colbert, N. Yee, and G. George, "The Digital Workforce and the Workplace of the Future," Academy of Management Journal, vol. 59, no. 3, pp. 731-739, 2016

[30] R. Henderson and I. Cockburn, "Measuring Competence? Exploring Firm Effects in Pharmaceutical Research," Strategic Manage J, vol. 15, no. S1, pp. 63-84, 1994

[31] M. Murawski and M. Bick, "Digital Competences of the Workforce - A Research Topic?," Business Process Management Journal, vol. 23, no. 3, pp. 721-734, 2017

[32] M. Feldman and M. Worline, "The Practicality of Practice Theory," Academy of Management Learning \& Education, vol. 15, no. 2, pp. 304-324, 2016

[33] M. S. Feldman, "Resources in Emerging Structures and Processes of Change," Organization Science, vol. 15, no. 3, pp. 295-309, 2004

[34] R. Kannan-Narasimhan and B. S. Lawrence, "How innovators reframe resources in the strategy-making process to gain innovation adoption," Strategic Management Journal, vol. 39, no. 3, pp. 720-758, 2018

[35] F. Svahn, L. Mathiassen, and R. Lindgren, "Embracing Digital Innovation in Incumbent Firms: How Volvo Cars Managed Competing Concerns," MIS Quart., vol. 41, no. 1, pp. 239-253, 2017

[36] J. A. Howard-Grenville, "Developing Issue-Selling Effectiveness over Time: Issue Selling as Resourcing," Organization Science, vol. 18, no. 4, pp. 560-577, 2007

[37] S. Taylor, People resourcing. CIPD Publishing, 2005.

[38] M. D. Platzer and G. J. Harrison, "The US automotive industry: National and state trends in manufacturing employment," 2009

[39] J. Lee and N. Berente, "Digital Innovation and the Division of Innovative Labor: Digital Controls in the Automotive Industry," Organ Sci, vol. 23, no. 5, pp. 14281447,2012

[40] J. Seawright and J. Gerring, "Case selection techniques in case study research: A menu of qualitative and quantitative options," Political research quarterly, vol. 61, no. 2, pp. 294308, 2008

[41] P. Gao, R. Hensley, and A. Zielke, "A road map to the future for the auto industry," McKinsey Quarterly, Oct, pp. 111,2014

[42] S. Carretero, R. Vuorikari, and Y. Punie, "The digital competence framework for citizens," Publications Office of the European Union, 2017

[43] L. Fernndez-Sanz, J. Gmez-Prez, and A. CastilloMartnez, "e-Skills Match," Comput. Stand. Interfaces, vol. 51, no. C, pp. 30-42, 2017
[44] R. Boselli et al., "WoLMIS: a labor market intelligence system for classifying web job vacancies," Journal of Intelligent Information Systems, vol. 51, no. 3, pp. 477-502, 2018

[45] M. 1. Vrang, A. Papantoniou, E. Pauwels, P. Fannes, D. Vandensteen, and J. D. Smedt, "ESCO: Boosting Job Matching in Europe with Semantic Interoperability," Computer, vol. 47, no. 10, pp. 57-64, 2014

[46] N. Berente, S. Seidel, and H. Safadi, "Research Commentary: Data-Driven Computationally Intensive Theory Development," Information Systems Research, vol. 30, no. 1, pp. 50-64, 2018

[47] G. George, E. C. Osinga, D. Lavie, and B. A. Scott, "Big Data and Data Science Methods for Management Research," Academy of Management Journal, vol. 59, no. 5, pp. 14931507, 2016

[48] W. H. Gomaa and A. A. Fahmy, "A survey of text similarity approaches," International Journal of Computer Applications, vol. 68, no. 13, pp. 13-18, 2013

[49] J. Beel, B. Gipp, S. Langer, and C. Breitinger, "Research-paper recommender systems: a literature survey," International Journal on Digital Libraries, vol. 17, no. 4, pp. 305-338, 2016

[50] A. Huang, "Similarity measures for text document clustering," 2008 2008, vol. 4, pp. 9-56

[51] G. Ertug, M. Gruber, A. Nyberg, and H. K. Steensma, "From the Editors - A Brief Primer on Data Visualization Opportunities in Management Research," vol. 61, no. 5, pp. 1613-1625, 2018

[52] D. L. Nazareth, E. S. Soofi, and H. Zhao, "Visualizing attribute interdependencies using mutual information, hierarchical clustering, multidimensional scaling, and selforganizing maps," in Proceedings of the 40th Hawaii International Conference on System Sciences - 2007, 2007 2007: IEEE,

[53] N. Nachar, "The Mann-Whitney U: A test for assessing whether two independent samples come from the same distribution," Tutorials in quantitative Methods for Psychology, vol. 4, no. 1, pp. 13-20, 2008

[54] V. Bilgram, A. Brem, and K. I. Voigt, "User-centric innovations in new product development - Systematic indentification of lead users harnessing interactive and collaborative online-tools," International Journal of Innovation Management, Article vol. 12, no. 3, pp. 419-458, 2008

[55] A. H. Van de Ven, "Running in packs to develop knowledge-intensive technologies," MIS Quarterly, 2005

[56] A. Tiwana, B. Konsynski, and A. A. Bush, "Research Commentary-Platform Evolution: Coevolution of Platform Architecture, Governance, and Environmental Dynamics," Information Systems Research, vol. 21, no. 4, pp. 675-687, 2010

[57] O. Henfridsson, J. Nandhakumar, H. Scarbrough, and N. Panourgias, "Recombination in the open-ended value landscape of digital innovation," Information and Organization, vol. 28, no. 2, pp. 89-100, 2018

[58] A. Lindberg, "Developing Theory through integrating Human \& Machine Pattern Recognition," J Assoc Inf Syst, vol. 21 , no. 1 , pp. $90-116,2020$ 